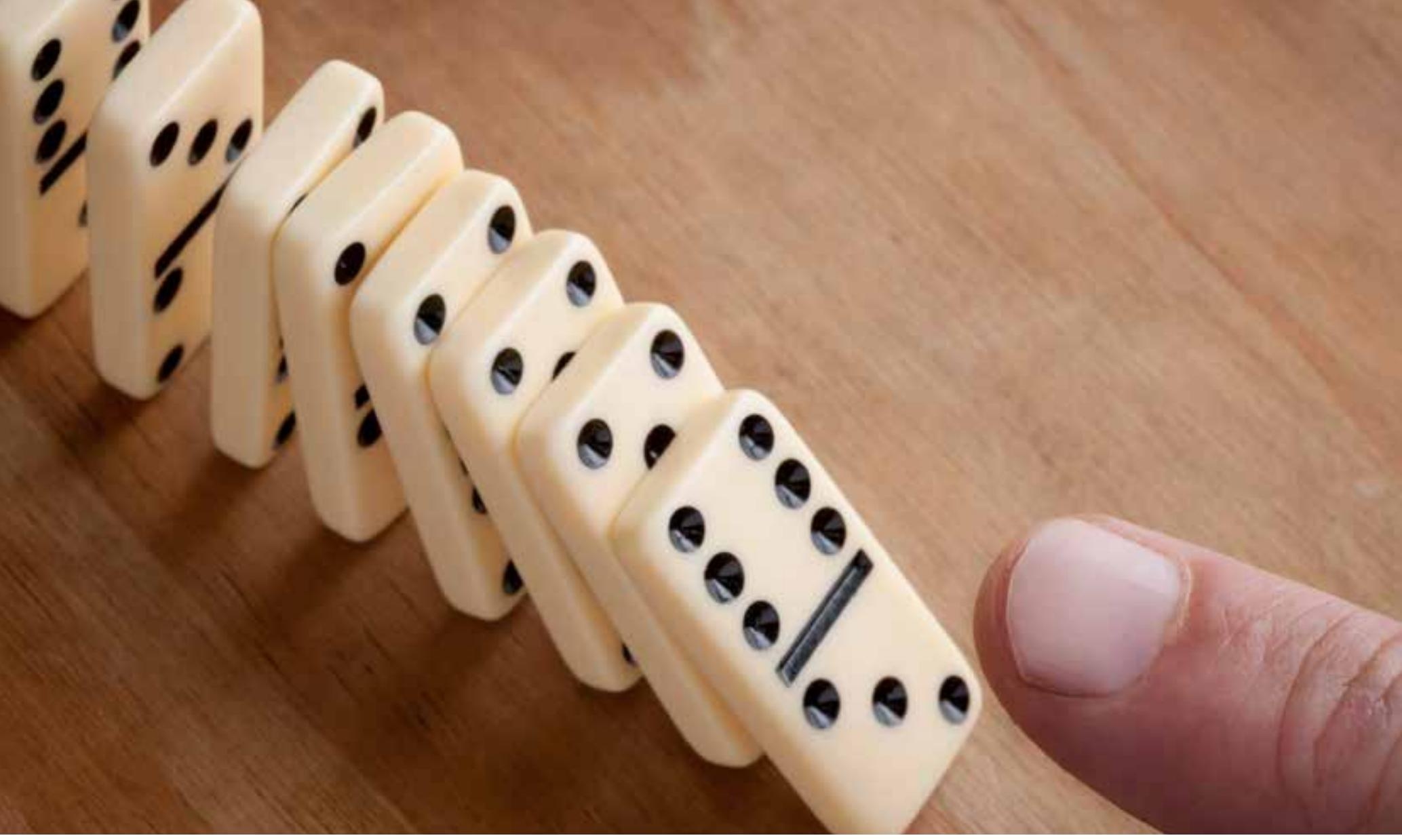

\title{
TAKING ACTION: PROGRESS AND CHALLENGES IN IMPLEMENTING NUTRITION POLICIES AND PROGRAMS
}

\section{TO BE EFFECTIVE, COMMITMENTS TO ACTION MUST BE IMPLEMENTED AND ENFORCED. THE IMPLEMENTATION OF POLICIES AND INTERVENTIONS DEPENDS}

on converting political commitment to practical action. How are governments and other stakeholders doing in implementing policies and interventions that reflect commitment?

In this chapter we track implementation of four different sets of actions: First we look at progress in creating an enabling environment for nutrition action through cross-sector governance structures - an area subject to a relatively high number of government policy and program commitments made at the 2013 Nutrition for Growth (N4G) Summit (see Chapter 4). While not policies themselves, the purpose of these governance structures is to drive development and implementation of policies and programs. Second, we examine policies that support breastfeeding - a practice that can address several different forms of malnutrition: wasting, stunting, and obesity. Third, we discuss policies that support healthy diets, and fourth, we look at coverage of direct nutrition interventions.
PROGRESS IN DEVELOPING INTERSECTORAL GOVERNANCE MECHANISMS FOR NUTRITION

The need for intersectoral governance for nutrition is now broadly recognized. Recommendation 3 of the Second International Conference on Nutrition (ICN2) Framework for Action encourages countries to develop national cross-government, intersectoral, multistakeholder mechanisms to oversee implementation of public policies. Chapter 4 showed that by far the most common policy and program commitments made at the 2013 N4G Summit concerned intersectoral mechanisms. Such mechanisms were critical in Brazil's efforts to address food security and nutrition (Chapter 1, Panel 1.5). The critical element 
in Brazil's experience was the establishment of a set of mechanisms between government ministries and between government, civil society, and social movements brought together through the National System for Food and Nutrition Security (SISAN). The existence of SISAN, and the fact that it was operational and had top-level support, enabled the effective coordination, implementation, and monitoring of the public policies.

The Scaling Up Nutrition (SUN) Movement has been vocal in its calls for multisector governance mechanisms as spaces to develop policies and plans. It calls for multiple sectors and stakeholders to work together in a truly coherent

This chapter explores persistent challenges and limited progress in implementing recommended nutrition policies and programs.

- Even when commitment is present, implementation is a challenge. In the presence of mandates to act, codes to guide, and evidence of impact, actual implementation of nutrition actions remains highly variable across countries and interventions. There is little evidence and analysis of where, why, and how such implementation gaps persist.

- Experience from existing intersectoral and interministerial mechanisms for implementing nutrition policies indicates they are more likely to succeed with top-level commitment, appropriate human and financial resources, and social participation.

- While breastfeeding is widely recognized as one of the best ways to improve nutrition, implementation of core policies and programs that promote breastfeeding need to be dramatically scaled up:

- Only 36 percent of countries implement all or many provisions of the International Code of Marketing of Breast-Milk Substitutes, which aims to encourage exclusive breastfeeding and appropriate use of complementary foods. This implementation figure has actually declined since the last assessment.

- Nearly a fifth of all countries have no data on maternity protection policies (such as workplace policies that support continued breastfeeding and childcare), suggesting a huge legislation gap. Nearly 70 percent of countries with data do not have policies for the provision of nursing or childcare facilities at the workplace.

- The first-ever analysis of the Baby-Friendly Hospital Initiative, which promotes breastfeeding in hospitals, shows that less than 28 percent of maternity facilities in 160 countries have been certified since 1991. Many have not been certified or recertified in the past few years, reflecting declining support for the initiative.

- Countries have made limited and uneven progress in implementing policies that promote healthy diets, which are essential to combating NCDs. For implementing three core recommendations of the World Health Organization (those on marketing to children, reducing salt, and reducing trans and saturated fats),

- two-thirds of countries have made no progress in implementing any of the three;

- only 10 percent of countries have made some progress in implementing all three, and a disproportionate number of these are high- or middle-income countries; and

- one-third of countries have implemented policies on salt reduction-the most widely implemented of the policies to date.

- The scale-up of nutrition-specific interventions for undernutrition has been slow and uneven: implementation of fortification and supplementation programs-such as vitamin A and zinc supplementation - has been stronger than health promotion-based approaches such as exclusive breastfeeding and dietary diversity promotion. Universalization of primary healthcare systems provides an opportunity to scale up these interventions further. 


\section{PANEL 5.1 LESSONS LEARNED FROM INTERSECTORAL GOVERNANCE MECHANISMS TO ADDRESS NUTRITION: NATIONAL NCD COMMISSIONS IN THE CARIBBEAN}

\section{MAISHA HUTTON AND SIR TREVOR HASSELL}

In 2007, the heads of the governments of the Caribbean Community (CARICOM) region held a seminal and first-of-its-kind summit on noncommunicable diseases (NCDs) in Port of Spain, Trinidad. ${ }^{1}$ As part of the resulting Port of Spain declaration, the heads of government called on countries to establish NCD commissions as mechanisms for the multisectoral prevention and control of NCDs at the national level-a recommendation first made in the Non-communicable Disease Prevention and Control Strategic Plan for the Caribbean Region 2003-2007. Because of the multiple causes and risk factors of NCDs, the commissions are designed to be the engine of a "whole-of-government" (intrasectoral) and "whole-of-society" (intersectoral) response.

By the end of 2014, 12 out of 20 countries in CARICOM had formed NCD commissions or analogous bodies. Seven of these were launched in 2011 or thereafter, likely in response to the 2011 UN High Level Meeting on NCDs. The Healthy Caribbean Coalition (HCC), a nongovernmental organization, has monitored and assessed the functioning of these commissions. A review of five of the commissions in 2014 found that four of the five had representatives from Ministries of Education and Agriculture (government) and from faith-based organizations, health-oriented civil society organizations, and trade unions (civil society). Three of the five had representation from the private health sector, manufacturers, and the media (private sector).
Since the Port of Spain NCD summit, national NCD commissions have had several successes in implementing programs and policies aimed at tackling NCDs. In 2015, HCC undertook a comprehensive review of all CARICOM national NCD commissions and found, for example, that the commission in Barbados had led national nutrition improvement and populationwide salt reduction campaigns. Well Bermuda, a national NCD commission equivalent, has successfully engaged multiple sectors in using health promotion strategies, with several memorandums of understanding signed between the Ministry of Health and lead agencies, and 15 out of 18 action plans implemented. The HCC reports a general sense that national NCD commissions have contributed to both a greater awareness of NCDs within countries and a multisectoral response to them.

However, national NCD commissions have also faced significant challenges in moving from governance structure to implementation of action. As of March 2016, only nine are currently active. A survey of five commissions in 2014 found that most of their chairs felt the commissions were not sufficiently action oriented and had no ability to guarantee implementation of their recommendations. Human and financial resource gaps hampered their programs. A lack of understanding of stakeholders' various roles and functions has been a barrier to implementing the requisite multisector, whole-of-society approach. Further, although these commissions were meant to serve as platforms for realizing a truly whole-of-society response to the NCD epidemic, it is now evident that there needs to be an interministerial task force or equivalent mechanism in which all sectors of government are truly engaged, thus creating a fertile environment for health in all policies in a whole-of-government response. The latter has not been achieved to any significant extent with the exception of a few territories. Defining relationships between national NCD commissions and Ministries of Health has been complex and sometimes cumbersome, often raising questions about roles and responsibilities and highlighting the lack of autonomy and implementation clout of these bodies. There have been challenges in monitoring and evaluating, and sharing information both within and among sectors, and consequently little evidence that knowledge and policies are being translated into behavior change.

In response to these challenges, $\mathrm{HCC}$ has made recommendations for strengthening national NCD commissions in the Caribbean, including ensuring stable financing, strengthening nonhealth government sectors, increasing participation by the private sector and civil society, and setting up a formal mechanism to allow for routine interaction between the minister of health and the members of the NCD commission. HCC is in the process of developing a national NCD commission implementation framework to support the establishment or strengthening of existing national commissions in the region. approach, combining high-level political commitment, effective laws and policies, aligned actions from all parts of society, and better resources to defeat malnutrition.
Evidence suggests that SUN countries are moving forward in developing intersectoral mechanisms. By September 2015, 48 of the 56 countries in the SUN Movement 
reported having an intersectoral, multistakeholder mechanism in place, although with varied degrees of functionality (Scaling Up Nutrition 2015). For example, of the N4G country signatories, the Democratic Republic of the Congo established its National Multisectoral Nutrition Committee in December 2015, and Zambia has developed subnational coordination structures at provincial, district, and ward/community level in all 14 priority districts. Most countries are working to improve engagement with civil society organizations (CSOs) and the science community as well as getting the private sector on board. With these mechanisms now established in many countries, the current challenge is to see that they function effectively. A 2015 self-assessment by SUN countries found that using the mechanisms to align actions and resources was proving a challenge.

Intersectoral governance is also recommended to facilitate the multisectoral action needed to address obesity and noncommunicable diseases (NCDs). At the international level, the World Health Organization (WHO) Global Coordinating Mechanism for NCDs began functioning in 2014 with the aim of facilitating coordination of activities; multistakeholder engagement; and action across sectors at the local, national, regional, and global levels. A range of independent initiatives designed to promote intersectoral, interdisciplinary coordination to spur action for obesity and NCDs have also been established, most recently the Lancet Commission on Obesity, which met for the first time in February 2016.

At the national level, the 2014 UN NCD review meeting produced a clear statement in support of mechanisms to lead, execute, and foster the multisectoral approach. It specifically recommended that countries should "consider establishing, as appropriate to the respective national context, a national multisectoral mechanism, such as a high-level commission, agency or task force for engagement, policy coherence and mutual accountability of different spheres of policy making" (United Nations 2014a, 6).

One region where the establishment of NCD commissions has been taken particularly seriously is the Caribbean, where 12 countries have established commissions. These commissions have led to some positive outcomes but also faced many challenges, as described in Panel 5.1. Like the SUN countries, these commissions have shown that having a mechanism is not in and of itself sufficient: a commission needs to be properly resourced with human and financial capacity and have real political clout to function effectively in its role of driving commitments to implemented action.

\section{PUBLIC POLICIES TO PROTECT AND PROMOTE BREASTFEEDING}

Breastfeeding is widely recognized as the best option for infant feeding, and the WHO recommends exclusive breastfeeding until 6 months of age, with continued breastfeeding up to 2 years of age or beyond with the addition of nutritionally adequate, safe, and appropriate complementary foods (WHO 2003). Following this recommendation saves lives, and the beneficial effects reach populations in all countries regardless of the stage of the countries' development. Breastfeeding has been found to protect against infant mortality and morbidity, especially from gastrointestinal infections; increase intelligence; and probably reduce NCD incidence, notably overweight and diabetes in later life. It is furthermore linked to a decreased risk of maternal breast cancer (Victora et al. 2016).

Many public policies can support breastfeeding, ranging from legislative protections to programs that support and counsel women. Here we review efforts to implement three actions aimed at improving breastfeeding rates for which data are available from a majority of countries: national implementation of the International Code of Marketing of Breast-Milk Substitutes, maternity protection, and baby-friendly hospitals.

\section{NATIONAL IMPLEMENTATION OF THE INTERNATIONAL CODE OF MARKETING OF BREAST-MILK SUBSTITUTES}

In 1981 the World Health Assembly (WHA) endorsed the International Code of Marketing of Breast-Milk Substitutes and subsequently passed 16 relevant resolutions to protect breastfeeding (WHO 1981). The WHA adopted the code in the form of a recommendation, and it is therefore not binding. For the code to take effect, countries must pass national legislation. However, countries' endorsement of the code represents an internationally stated commitment to implementing it.

In the 2014 Global Nutrition Report, we reported that more than half (54 percent) of the 164 countries with data available had succeeded in enacting laws encompassing all or many of the provisions in the code (IFPRI 2014). Using updated data compiled by WHO, UNICEF, and the International Baby Food Action Network (IBFAN) (2016), we now present a more up-to-date picture of the global status of implementation of the code.

Data are now available for 183 of 193 countries (95 percent). Figure 5.1 shows the global and regional number and percentage of 193 countries in each stage of implementation of the code. As of 2016, 70 of 193 countries (36 percent) covered all or many provisions of the code. In Africa and Asia, the proportion of countries with all or 


\section{FIGURE 5.1 Legal status of the breast-milk marketing code in UN countries by region, 2016}

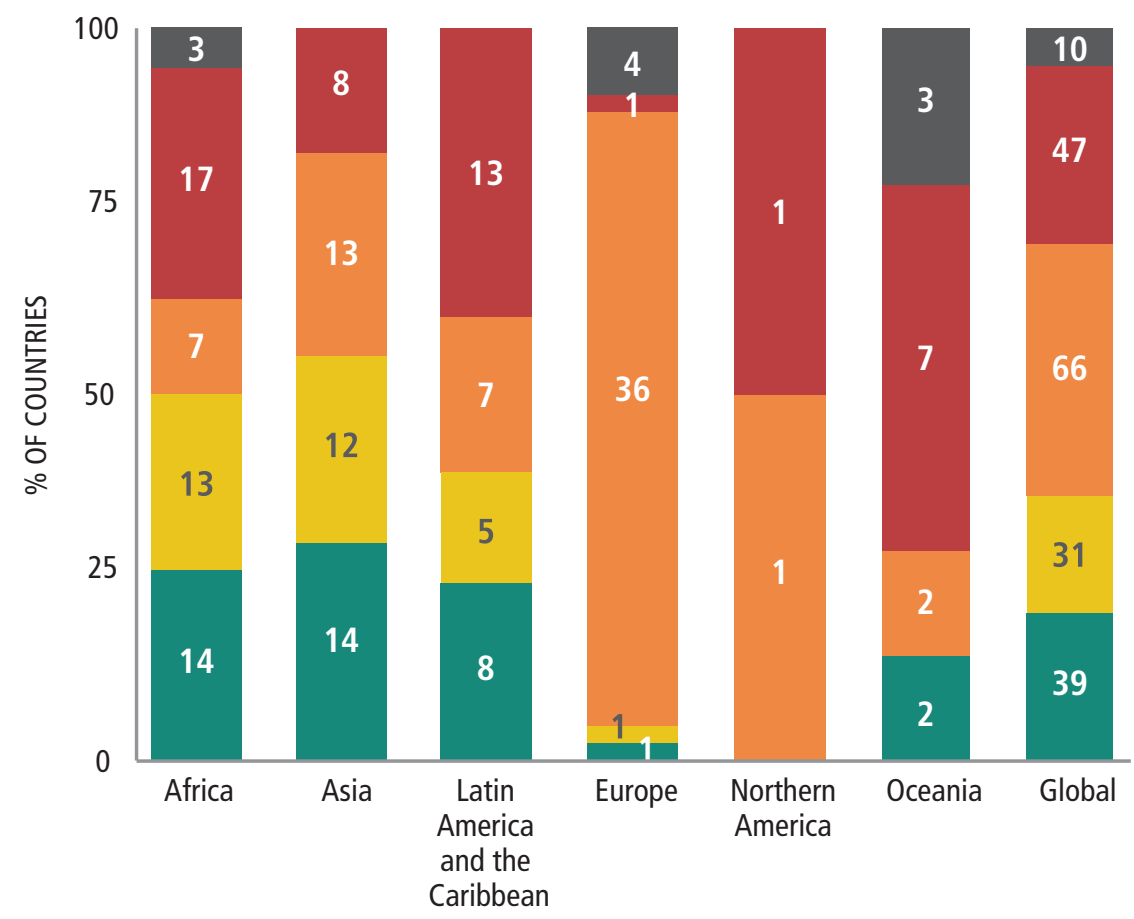

Source: Authors, based on data from WHO, UNICEF, and IBFAN (2016).

Note: The number of countries is shown as numbers on the bars. Percentage of countries is shown as the area of bars.

many provisions was higher (50 percent and 55 percent, respectively) than in the rest of the world. There were no legal provisions in place in 47 countries (24 percent). Owing to a reassessment of the provisions in countries, the number of countries with provisions in place has actually declined from 89 of 193 (46 percent) in 2014. ${ }^{1}$

For the code to have the full effect intended by the WHA 35 years ago, many more countries will need to pass legislation that includes all the articles in the code, implement meaningful penalties for noncompliance, and establish reliable monitoring systems. A positive step in this direction is the recent creation of the Network for Global Monitoring and Support for Implementation of the International Code of Marketing of Breast-Milk Substitutes and Subsequent Relevant WHA Resolutions (NetCode) by the WHO in collaboration with UNICEF and nongovernmental organizations dedicated to breastfeeding and child health.

\section{MATERNITY PROTECTION}

A recent report on the global childcare crisis reviewed existing data on the economic and social effects of childcare demands on women (ODI 2016). The report highlights the need to extend care-related policies such as support for breastfeeding and maternity protection to the informal sector, as an important measure to improve pay parity in the workplace and reduce the economic penalty that working mothers pay as a result of inaccessible childcare and weak workplace policies to support motherhood.

In the Global Nutrition Report 2014, we examined implementation across all 193 countries of the International Labour Organization's Convention 183, which provides maternity leave protection (IFPRI 2014). We found that the convention, which commits countries to guaranteeing 14 weeks of maternity leave paid at 66 percent of previous earnings by social security or general revenue, had been ratified by 86 countries (51 percent of the 169 countries with data). Ratification is only the first step; each ratifying country must then implement the provisions through national laws or regulations. Here we build on the Global Nutrition Report 2014 analysis to examine data on two further indicators of workplace policies that support continued breastfeeding when women return to work after giving birth: entitlement to paid nursing breaks, and childcare or nursing facilities provided by the employer. The guarantee of paid breastfeeding breaks is associated with higher rates of exclusive breastfeeding (Heymann et al. 2013). 


\section{FIGURE 5.2 Status of legislation supporting exclusive breastfeeding, 2013}

\section{a. Countries with legislation ensuring nursing breaks ${ }^{\mathrm{a}}$}

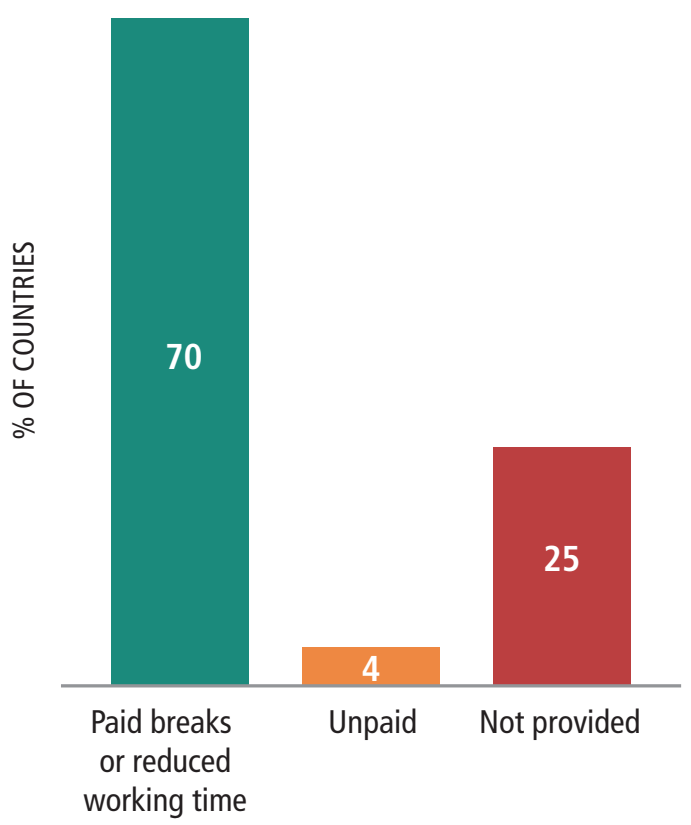

b. Countries with legislation ensuring provision of nursing or childcare facilities at or near the workplace

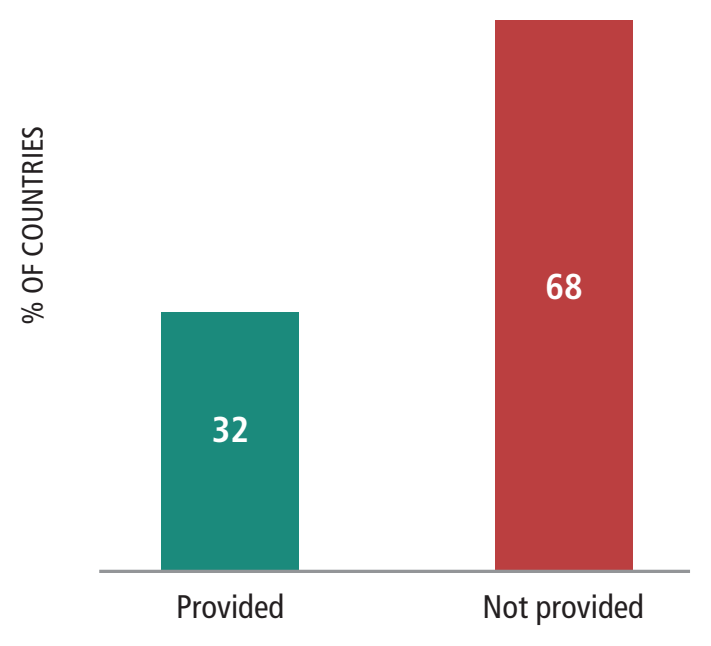

Source: Authors, based on data from ILO (2014).

Note: Figure 5.2a shows results for the 159 countries with data on this issue. Figure $5.2 \mathrm{~b}$ shows results for the 157 countries with data on this issue. ${ }^{\text {a }}$ Percentages do not total 100 because of rounding.

Nearly one-fifth of all countries had no data available on legislation for these policies (ILO 2014), highlighting a big data gap. For the countries with data, 70 percent had legislation in place entitling women to paid nursing breaks or a reduction of working time to breastfeed or to express breast milk during the workday (Figure 5.2a). The duration of the entitlement ranged from 1-5 months to until the child's second birthday (32 countries do not specify any duration). However, 68 percent of countries with data did not have legislation for the provision of any nursing or childcare facilities at the workplace (Figure 5.2b).

\section{THE BABY-FRIENDLY HOSPITAL INITIATIVE}

For the first time, we report on the implementation of the Baby-Friendly Hospital Initiative (BFHI). Launched by WHO and UNICEF in 1991, the initiative aims to support breastfeeding in facilities that provide maternity services. It certifies whether hospitals adhere to a set of 10 specific steps that address the domains of policy, human resources, promotion and support, protection from breast-milk substitutes, and physical structure to ensure that mothers and babies room together.

There is no global dataset on the BFHI. The data we present here show country-level coverage in 127 countries for which data are available from five different sources: WHO's Global Nutrition Policy Review (WHO 2013b); UNICEF's NutriDash Survey (UNICEF 2014); a Pan American Health Organization report titled The Baby Friendly Hospital Initiative in Latin America and the Caribbean: Current Status, Challenges and Opportunities (PAHO 2015a); the World Breastfeeding Trends initiative of the International Baby Food Action Network (WBTi 2016); and the Eighth Meeting of BFHI Coordinators from Industrialized Countries, Eastern Europe, and the Commonwealth of Independent States (CEE/CIS) Survey (Stufkens 2014).

The data describe the percentage of a country's maternity facilities that have ever been designated as baby friendly. We do not have information on how many of these facilities have been reassessed or continue to follow BFHI policies. A more comprehensive global database will be made available through WHO later this year.

Between 2007 and 2014, 91 countries reported low coverage levels - that is, less than 40 percent of facilities were baby friendly (Figure 5.3); 14 of these countries reported that not a single hospital or maternity facility in 
the country had ever received BFHI certification. Only 3 countries (Bahrain, Cuba, and Fiji) reported 100 percent $\mathrm{BFHI}$ coverage. These estimates may change when new data become available, but overall they indicate low levels of implementation.

It has evidently proved a challenge to sustain $\mathrm{BFHI}{ }^{2}$ Throughout the 1990s, the initiative benefited from strong political support and international investment in training and evaluation. As a result, numerous facilities were certified, leading to significant improvements in breastfeeding (Perez-Escamilla et al. 2016). Globally, an estimated 27.5 percent of maternity facilities in 160 countries have been certified since 1991 (Labbock 2012).

However, a recent estimate for Latin America and the Caribbean shows that although 8 percent of facilities have been certified overall, only 2 percent had been certified or recertified in the preceding five years, and 40 percent of countries had no certifications or recertifications during that period (PAHO 2015a). In the past five years, only 3.5 percent of facility births have occurred in certified facilities, compared with a 25-year average of 15.0 percent.

As a result of declining support and investment, implementation of the initiative has been uneven, often depending on a single person in the Ministry of Health with a limited or no budget. One key way to increase the

\section{FIGURE 5.3 Coverage of facilities ever designated as baby friendly in 127 countries, data collected 2007-2014}

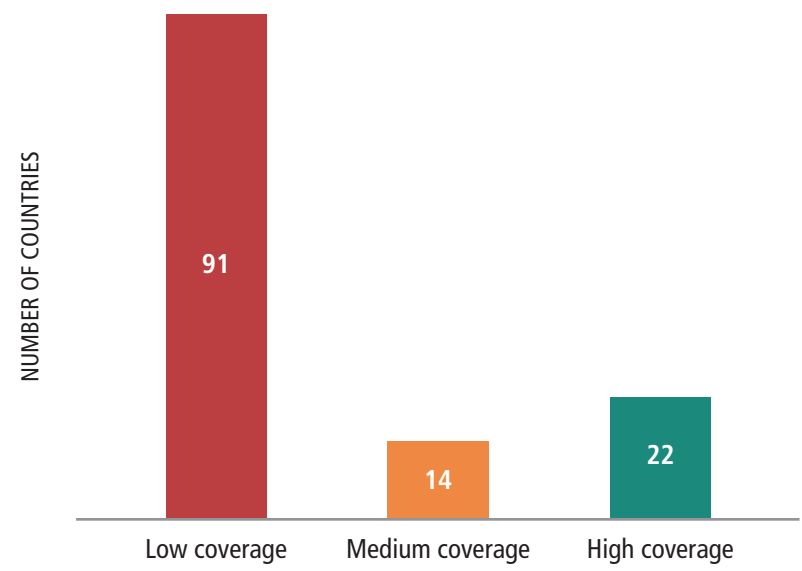

Source: Authors, based on data from WHO (2013b); WBTi (2016); PAHO (2015a); Stufkens (2014); UNICEF (2014).

Note: Low coverage $=<40 \%$ of hospitals are designated as baby friendly, Medium coverage $=40-60 \%$, High coverage $=>60 \%$. Year of data collection does not imply date of certification or timely recertification of facilities. sustainability of the initiative is to link the certification process to broader hospital accreditation systems. This tactic has been used, for example, in Viet Nam, where BFHI's 10 steps to successful breastfeeding have been incorporated into the National Hospital Quality Criteria and Accreditation System.

Another key mechanism to enhance sustainability is strategic data collection to measure coverage; the appropriate use of information collected is also essential. For example, in 2007, the US Centers for Disease Control and Prevention instituted an annual state-by-state report card, which has documented that the proportion of births occurring in baby-friendly hospitals in the United States increased from less than 2 percent in 2007 to nearly 8 percent in 2014 (PAHO 2015a).

\section{PUBLIC POLICIES TO PROMOTE HEALTHY DIETS}

Policies to promote healthy diets, to which governments have committed in international forums, are expected to become more important in the era of the new Sustainable Development Goals (SDGs), which include a specific target on reducing noncommunicable diseases. Such policies also form one of the three core planks of the Report of the Commission on Ending Childhood Obesity, published by $\mathrm{WHO}$ in 2016 . The report recommends that countries "implement comprehensive programmes that promote the intake of healthy foods and reduce the intake of unhealthy foods and sugar-sweetened beverages by children and adolescents" (WHO 2016o, viii).

The report's recommendations follow from a series of international recommendations of policies to promote healthy diets initiated in 2004 with the WHO Global Strategy on Diet, Physical Activity, and Health. In the 2011 UN political declaration on NCDs, countries pledged to promote healthy diets through public policies to do the following:

- Implement the WHO recommendations on marketing of foods and nonalcoholic beverages to children

- Reduce salt, sugars, and saturated fats

- Eliminate trans fats

- Encourage policies that support production of healthy foods

Here we report on progress in implementing three of these policies: implementation of the WHO recommendations, salt reduction strategies, and policies to reduce saturated and trans fats. These policies were selected by the WHO for its required reporting to the 2017 UN General Assembly. ${ }^{3}$ 


\section{PANEL 5.2 TRANSLATING GLOBAL TARGETS TO NATIONAL ACTION: SMART SALT POLICIES IN ARGENTINA}

\section{CHESSA LUTTER}

$T^{n}$ he Argentinian law on salt reduction commits the government to reducing salt intake to 5 grams per person per day by 2020 through a series of measures, including a gradual reduction of salt in bread and other processed foods, and a communication campaign with the slogan "Less salt, more life" (Menos sal, más vida, in Spanish).

The policy aims to be SMART (specific, measurable, achievable, relevant, and time bound). It is clearly both specific and measurable. It is also likely to be achievable, because studies conducted in the country show that 70 percent of salt intake is from processed foods, especially bread. Therefore, a focus on processed foods and bread for salt reduction will address a major portion of salt intake. The commitment is also highly relevant; research conducted in the country estimated that for each gram of salt reduction, 2,000 annual deaths from cardiovascular disease could be avoided. Last, it is time bound. Interim two-year targets were established, such as reduction of salt in bread by a certain amount. The salt content in bread and other processed foods is measured, as is intake (through 24-hour urine collection), and data are analyzed at a national laboratory.

Between 2011 and 2015, average daily salt intake fell by 2.0 grams, from 11.2 to 9.2 grams per day. While significantly more work is needed to bring down intake to the 5-gram target, it is estimated that this decrease resulted in 4,040 fewer deaths per year during that period.
Our analysis is based on data from the self-reported NCD Country Capacity Survey conducted in 2014, which collected information from 193 countries (WHO 2015c). We reported on the number of countries that (1) report "any progress" on implementation, whether fully or partially achieved, and (2) report "no progress" or have inadequate data to assess progress.

As shown in Figure 5.4, progress has been extremely limited: governments are far behind in implementing these widely recommended policies to prevent obesity and NCDs. Of 193 countries, only 20 (10 percent) have made some progress on all three indicators; 120 (62 percent) have made no progress. Fifty-three countries (28 percent) reported fully achieving at least one or two of the three.

Of the 193 countries covered in the NCD capacity survey, 24 percent say they have implemented WHO's 2010 recommendations intended to guide national efforts to restrict food marketing to children (WHO 2010b). However, the criteria for assessing whether a country has implemented the recommendations are not clear. It could mean, for example, that there is a voluntary agreement on some aspect of marketing, a policy statement about why the issue is important, a comprehensive action plan, or a specific implemented action that achieves the objective set by the recommendations: to reduce the exposure of children to, and power of, marketing. The World Cancer Research Fund International database, NOURISHING, which tracks confirmed information on implementation of specific policies, reports that only 16 countries have implemented restrictions on marketing to children that aim to achieve these objectives (WCRF International 2016). This represents just 8 percent of the 193 countries.

\section{FIGURE 5.4 Number of countries that have implemented healthy diet policies}

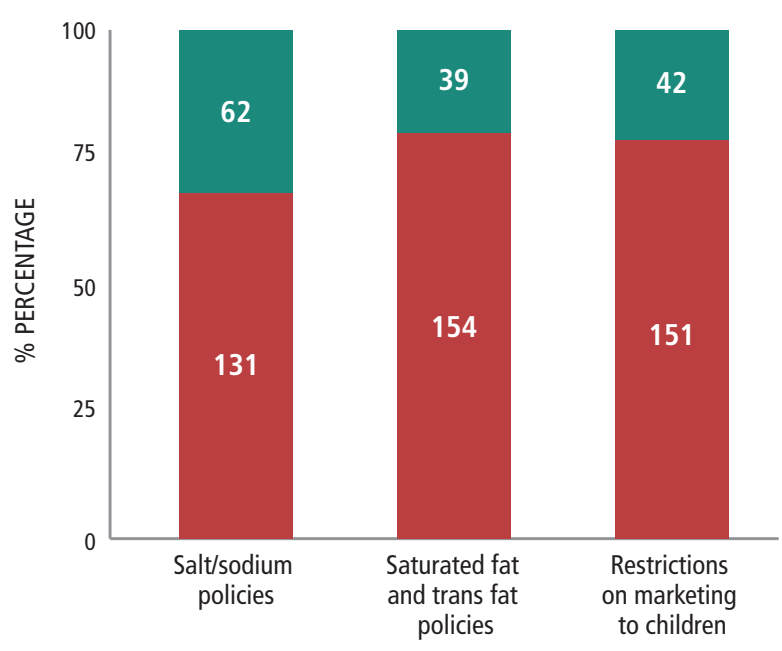

Some progress

No progress

Source: Authors, based on data from WHO (2015c).

Note: Total number of countries $=193$. The number of countries is shown as numbers on the bars. Percentage of countries is shown as the area of bars. 
More work is needed to clarify how to monitor the WHO recommendations.

The policy that has been most widely implemented is sodium/salt reduction; 62 countries (one-third) have implemented such policies (WHO 2015c). In an independent assessment of salt reduction strategies, Trieu and colleagues (2015) identified 75 countries with a national salt reduction strategy, more than double the number reported in a similar review done in 2010 . They found that the majority of programs are multifaceted and include industry engagement to reformulate products (61 countries), establishment of sodium content targets for foods (39), consumer education (71), front-of-pack labeling (31), taxation of high-salt foods (3), and interventions in public institutions (54). Legislative action related to salt reduction, such as mandatory targets, front-of-pack labeling, food procurement policies, and taxation, has been implemented in 33 countries.

As a region, Latin America has been particularly active on salt reduction. As of 2015, 12 governments in Latin America and the Caribbean had implemented national initiatives to reduce salt intake. In addition to the 12 governments with national initiatives, as of 2015 another 9 countries had subnational programs or had done research on salt reduction. Argentina, for example, has implemented a SMART (specific, measurable, achievable, relevant, and time bound) approach to salt reduction, as described in Panel 5.2.

One policy area that has undergone significant developments in recent years is the adoption of taxes on sugar-sweetened beverages and foods high in fat, sugar, and salt. According to the NOURISHING database (WCRF International 2016), 14 countries now have health-related food and beverage taxes (and the United Kingdom will implement a tax in 2018), 6 of which have been implemented since 2014. In one of those countries, Mexico, new evidence published in 2016 suggests that the tax is associated with declines in expenditure on sugar-sweetened beverages, with a larger effect among households with lower incomes (Colchero et al. 2016). Chile also implemented a sugar-sweetened beverage tax in 2015, as well as fully achieving two of the three $\mathrm{WHO}$ policy indicators. Panel 5.3 tells the story of the people and processes in Chile that have converted political commitment into action.

A disproportionate number of countries that have implemented policies are either high-income countries like Chile or upper-middle-income countries like Argentina and Mexico. Of the 20 countries that reported having fully achieved all three policies, 13 were high-income countries, 6 upper-middle-income, and 1 low-income. Of the countries that had implemented no policies at all, the largest share -33 percent (40 countries) —were lower-middle-income countries. The scores vary significantly across regions: 96 percent of African, 60 percent of Asian, 57 percent of Oceanian, 58 percent of Latin American, and 30 percent of European countries did not achieve full scores on any indicators. The two Northern American countries reported having achieved two or all three indicators.

While countries are making progress in implementing these policies to protect and promote healthy diets, and some countries stand out in their commitments to actionnotably in Latin America-the bigger picture is the same as reported in Global Nutrition Report 2015: patchy progress with huge implementation gaps. Gaining support for these policies from stakeholders in international agencies, government, donors, and development agencies historically concerned with undernutrition may be one way of encouraging greater political commitment to action. Some policies can do "double duty" in addressing different forms of malnutrition. As shown in Chapter 4, the N4G commitments need to be realigned to encourage countries to develop and implement specific policies and programs (Chapter 4). A new set of commitments for the post-ICN2, SDG era would, as called for in Chapter 4, help move the process of international commitments to public policies forward for breastfeeding, healthy diets, and as discussed in the next section, coverage of direct nutrition interventions.

\section{COVERAGE OF DIRECT INTERVENTIONS TO REDUCE UNDERNUTRITION}

The Global Nutrition Report 2015 showed the availability of coverage data for 12 proven interventions recommended by WHO (2013a) and by Bhutta and colleagues (2013) to address maternal and child undernutrition (Table 4.5 in Global Nutrition Report 2015). We also tracked data for six of these interventions, consisting of nine indicators (Table 4.6 in Global Nutrition Report 2015).

This year, we track 13 indicators, covering the same six interventions (Table 5.1). ${ }^{4}$ Data, however, are from 2005 to 2015 , and several new indicators have been added. These 13 represent nearly all coverage or proxy coverage indicators for pregnant women and children included in the Demographic and Health Surveys.

New additions to this year's report include children 6-23 months fed the minimum meal frequency, children 6-59 months given iron supplements in the past seven days, women who received iron and folic acid during their most recent pregnancy, and women who received iron and folic acid during the most recent pregnancy and did not take it. We furthermore show the three countries with the 


\section{PANEL 5.3 IMPLEMENTING PUBLIC POLICIES TO PROMOTE HEALTHY DIETS IN CHILE}

\section{CAMILA CORVALAN AND MARCELA REYES}

In the past five years, the Chilean government has passed a series of regulations to improve the population's dietary intake, attempting to curb the ongoing obesity and noncommunicable disease (NCD) epidemic. In 2014, the government implemented an 8 percent tax on sugar-sweetened beverages relative to other beverages. In July 2016, food companies will be required to place front-of-package warning labels on processed foods and beverages high in sugars, sodium, saturated fats, and energy, and they will be prohibited from advertising and marketing these products to children 14 and younger. The marketing restriction represents the most comprehensive in the world to date.

The implementation of these regulations is the result of almost 10 years of intense discussions involving sectors such as health, agriculture, economy, and social development, as well as several actors, including politicians, researchers, and food industry representatives, among several others. During these years, key leaders continuously pushed for the approval and implementation of these regulations.

- In academia, a public health nutrition professor played a key role by leading the WHO committee on chronic disease prevention. He actively disseminated data on Chile's epidemic of obesity and NCDs as well as stressing the need for larger-scale actions. His participation has been critical for involving policy makers and providing credibility and scientific support to the entire process.

- In the Senate, a medical doctor took the challenge, presenting a first regulatory draft and pushing for its approval. Over these years, this legislator has been key in raising awareness of this topic in the Senate and in public opinion.

- In government, the chair of the nutrition department of the Ministry of Health has consistently led the process by maintaining a consistent point of view and prioritizing this agenda.

The Ministry of Health also convened several expert advisory committees to provide scientific advice and served as a hub for continuous communication among different sectors and actors. It did, however, have to make compromises in order to move toward implementation. For example, to get the approval of the agriculture and economic sectors in government, the Ministry of Health negotiated a phased implementation; the regulations will thus become increasingly strict over three years.

The process of implementation is still in the early phases. Its long-term sustainability depends on the strength of the government and its ability to maintain support from the different sectors, as well as on increased participation by civil society, which has not played a significant role in the adoption of the measures to date.

Will it be effective? An evaluation plan involving international researchers is already in place to assess whether the policies will attain their objective of improving diets among the Chilean population. highest percentage of coverage for 12 of these indicators, and the three countries with the lowest (Figure 5.5).

The analysis shows that countries are on average doing better on supplementation and fortification programs than on health promotion-based approaches. Many actors have played a role in advancing the commitment to implement fortification programs. Panel 5.4 provides an example of how private-sector engagement has played a key role in enhancing salt iodization, and Panel 5.5 highlights the role played by a nongovernmental organization.

In other supplementation and fortification programs, countries are doing well on providing vitamin A supplementation, with median coverage of 79 percent, ${ }^{5}$ and on providing iron and folic acid supplementation to women during their most recent pregnancy, with a median coverage of 78 percent. However, the median proportion of women in countries with data who did not take the supplement was 21 percent (ranging from 3 to 83 percent).

For the health promotion-based approaches, including complementary feeding interventions for infants and young children 6-23 months old, the three indicators used reflect low rates of coverage across countries. The lowest rate is for minimum acceptable diet, ${ }^{6}$ with a median of only 15 percent (ranging from 3 to 72 percent). The best median coverage for complementary feeding interventions is minimum meal frequency, ${ }^{7}$ with a median of 57 percent. As 


\section{TABLE 5.1 Coverage of interventions and practices to address maternal and child malnutrition}

\begin{tabular}{|c|c|c|c|c|c|c|}
\hline \multirow{2}{*}{$\begin{array}{l}\text { Coverage or practice } \\
\text { indicator }\end{array}$} & \multirow{2}{*}{$\begin{array}{l}\text { Associated intervention } \\
\text { recommended by Bhutta et } \\
\text { al. (2013) (target population) }\end{array}$} & \multirow{2}{*}{$\begin{array}{l}\text { Number of } \\
\text { countries } \\
\text { with data }\end{array}$} & \multicolumn{4}{|c|}{ Rate of coverage or practice for countries with data (\%) } \\
\hline & & & Minimum & Maximum & Mean & Median \\
\hline $\begin{array}{l}\text { Children 0-59 months with diar- } \\
\text { rhea who received zinc treatment }\end{array}$ & $\begin{array}{l}\text { Zinc treatment for diarrhea } \\
\text { (children 0-59 months) }^{*}\end{array}$ & 39 & 0.1 & 15 & 3 & 2 \\
\hline $\begin{array}{l}\text { Early initiation of breastfeeding } \\
\text { (proportion of infants who were } \\
\text { put to the breast within one hour } \\
\text { of birth) }\end{array}$ & $\begin{array}{l}\text { Protection, promotion, and } \\
\text { support of breastfeeding * }\end{array}$ & 125 & 14 & 93 & 52 & 52 \\
\hline $\begin{array}{l}\text { Infants }<6 \text { months who were } \\
\text { exclusively breastfed }\end{array}$ & $\begin{array}{l}\text { Protection, promotion, and } \\
\text { support of breastfeeding * }\end{array}$ & 122 & 0.3 & 87 & 38 & 37 \\
\hline $\begin{array}{l}\text { Children } 12-15 \text { months who } \\
\text { were breastfed }\end{array}$ & $\begin{array}{l}\text { Protection, promotion, and } \\
\text { support of breastfeeding * }\end{array}$ & 122 & 12 & 98 & 69 & 72 \\
\hline $\begin{array}{l}\text { Children 6-23 months fed } 4+ \\
\text { food groups (minimum dietary } \\
\text { diversity) }\end{array}$ & $\begin{array}{l}\text { Promotion of complementary } \\
\text { feeding for food-secure and } \\
\text { food-insecure populations (chil- } \\
\text { dren 6-23 months)* }\end{array}$ & 60 & 5 & 90 & 36 & 28 \\
\hline $\begin{array}{l}\text { Children } 6-23 \text { months fed the } \\
\text { minimum meal frequency }\end{array}$ & $\begin{array}{l}\text { Promotion of complementary } \\
\text { feeding for food-secure and } \\
\text { food-insecure populations (chil- } \\
\text { dren 6-23 months)* }\end{array}$ & 82 & 12 & 94 & 56 & 57 \\
\hline $\begin{array}{l}\text { Children } 6-23 \text { months fed with } \\
\text { three IYCF practices (minimum } \\
\text { acceptable diet) }\end{array}$ & $\begin{array}{l}\text { Promotion of complementary } \\
\text { feeding for food-secure and } \\
\text { food-insecure populations (chil- } \\
\text { dren 6-23 months)* }\end{array}$ & 50 & 3 & 72 & 22 & 15 \\
\hline $\begin{array}{l}\text { Children } 6-59 \text { months who } \\
\text { received two doses of vitamin A } \\
\text { supplements in } 2014\end{array}$ & $\begin{array}{l}\text { Vitamin A supplementation } \\
\text { (children 0-59 months)* }^{*}\end{array}$ & 57 & 0 & 99 & 65 & 79 \\
\hline $\begin{array}{l}\text { Children 6-59 months given iron } \\
\text { supplements in past seven days }\end{array}$ & $\begin{array}{l}\text { Neither Bhutta et al. (2013) nor } \\
\text { WHO (2016d) recommend this } \\
\text { intervention }\end{array}$ & 51 & 1 & 45 & 14 & 12 \\
\hline $\begin{array}{l}\text { Household consumption of } \\
\text { adequately iodized salt }\end{array}$ & Universal salt iodization* & 83 & 0.2 & 100 & 57 & 61 \\
\hline $\begin{array}{l}\text { Women with a birth in last five } \\
\text { years who received iron and folic } \\
\text { acid during their most recent } \\
\text { pregnancy }\end{array}$ & $\begin{array}{l}\text { Multiple micronutrient supple- } \\
\text { mentation (pregnant women) }\end{array}$ & 57 & 17 & 97 & 71 & 78 \\
\hline $\begin{array}{l}\text { Women with a birth in last five } \\
\text { years who received iron and } \\
\text { folic acid during the most recent } \\
\text { pregnancy and did not take it }\end{array}$ & $\begin{array}{l}\text { Multiple micronutrient supple- } \\
\text { mentation (pregnant women) }\end{array}$ & 55 & 3 & 83 & 27 & 21 \\
\hline $\begin{array}{l}\text { Women with a birth in last five } \\
\text { years who received iron and folic } \\
\text { acid in the most recent pregnan- } \\
\text { cy and took it for } 90+\text { days }\end{array}$ & $\begin{array}{l}\text { Multiple micronutrient supple- } \\
\text { mentation (pregnant women) }\end{array}$ & 56 & 0.4 & 82 & 28 & 29 \\
\hline
\end{tabular}

Source: Authors, based on data from Kothari (2016) and UNICEF (2016d), the latter based on Multiple Indicator Cluster Surveys, Demographic and Health Surveys, and other nationally representative surveys conducted between 2005 and 2015.

Note: * = interventions recommended by WHO (2016d). Multiple micronutrient supplementation is recommended by Bhutta et al. (2013). Data from before 2005 have been excluded from this table pending WHO ratification of this recommendation. For India, new data from Rapid Survey on Children 2013-2014 are used where applicable. IYCF = infant and young child feeding. 


\section{FIGURE 5.5 Countries with the highest and lowest coverage rates of 12 interventions and practices to address maternal and child malnutrition}

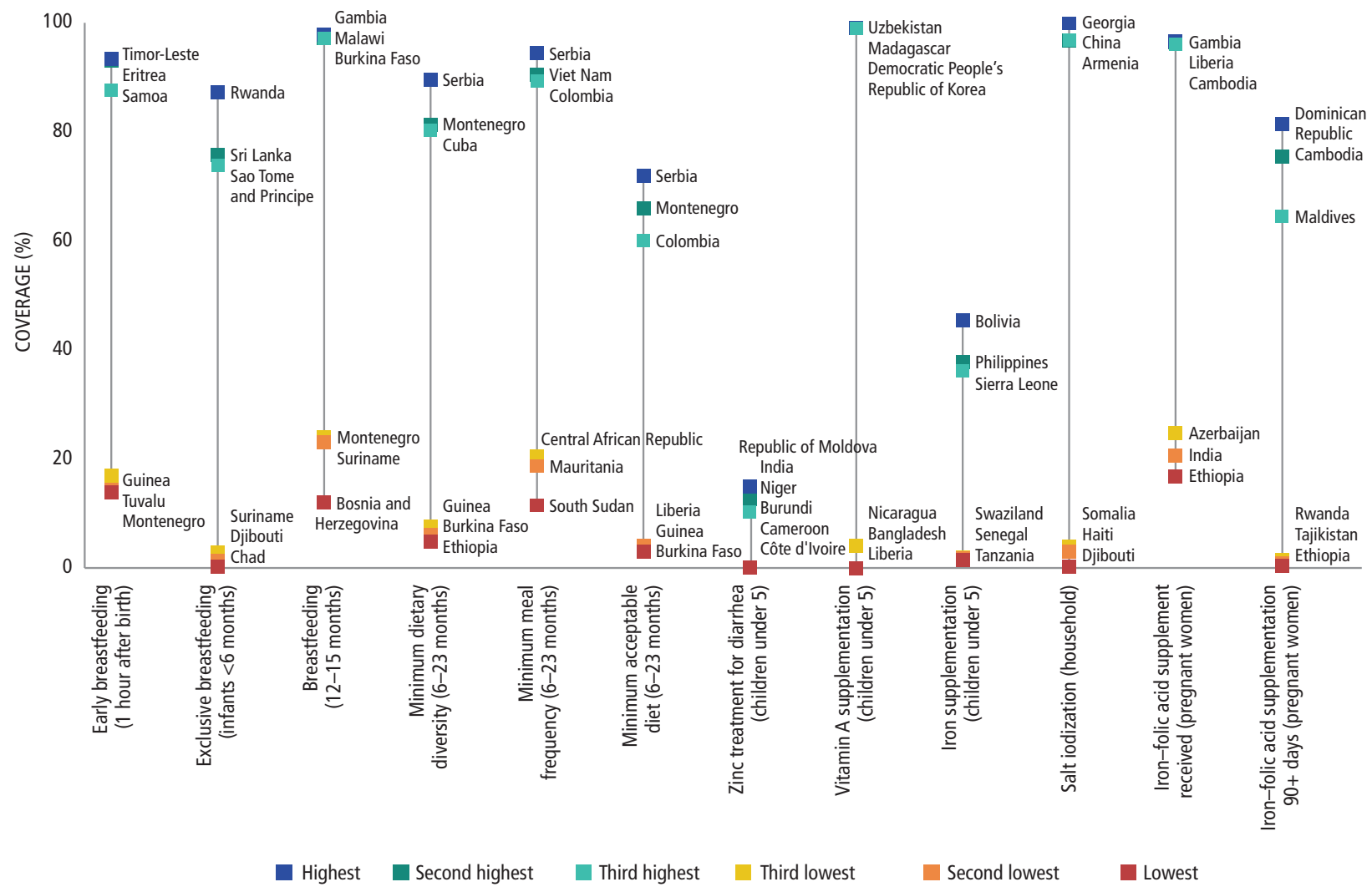

Source: Authors, based on data from Kothari (2016) and UNICEF (2016d), the latter based on Multiple Indicator Cluster Surveys, Demographic and Health Surveys, and other nationally representative surveys conducted between 2005 and 2015.

we have said in previous Global Nutrition Reports, improving these numbers from their very low levels is a high priority.

Outcome indicators that can be influenced through interventions that focus on the protection, promotion, and support of breastfeeding include initiation of breastfeeding within one hour of birth, exclusive breastfeeding of infants younger than 6 months, and continued breastfeeding at 1 year and at 2 years. Among this group of indicators, the median for exclusive breastfeeding is lowest, indicating the need to strengthen program inputs. This indicator is one where program efforts have notably led to successful increases and where withdrawal of program efforts has been accompanied by a subsequent deterioration of rates.

Continued breastfeeding at one year, on the other hand, has the highest median among this group of indicators, at 72 percent. Rates for continued breastfeeding at one year have, however, been relatively steady over the last few decades and thus appear not to be influenced by any recent program efforts.
There is more work to be done to clarify the relationship between these practice indicators and the implementation and quality of policies and interventions such as those reviewed above. Do coverage practice indicators reflect policy adoption and implementation, other factors, or both? If so, in what ways? Knowing what needs to be done to improve infant and young child feeding practices is challenging when it is not clear what policies and interventions have been implemented, nor their quality.

Some coverage data are available on the management of severe acute malnutrition (SAM) through outpatient care with ready-to-use therapeutic foods and inpatient care with hospitalization and treatment in facilities (Figure 5.6 presents coverage data from the Coverage Monitoring Network, or CMN). ${ }^{8}$ Using only 2014 and 2015 data for the 17 countries CMN reported on, coverage assessment estimates are available for 58 of 102 , or 57 percent, of district locations in 14 countries. ${ }^{9}$ Coverage rates are below 50 percent in 33 of 58 district locations. These numbers 


\section{PANEL 5.4 ENGAGING THE PRIVATE SECTOR IN ETHIOPIA TO IMPROVE IODIZED SALT ACCESS}

\section{COREY L. LUTHRINGER, ALEM ABAY, AND GREG S. GARRETT}

ince 2011, Ethiopia has achieved tre-

mendous progress in improving iodine nutrition by iodizing salt. Ethiopia has long struggled with a high prevalence of micronutrient malnutrition among its population. In 2005, iodine intakes were very low. National coverage of iodized salt (containing any amount of iodine) was 4.2 percent, 83 percent of schoolchildren had iodine deficiency, and nearly 40 percent of children were identified with goiter (EHNRI, FMoH, and UNICEF 2005).

By the end of 2014, however, more than 95 percent of households had access to iodized salt (containing any amount of iodine), and 42.7 percent of households had access to adequately iodized salt. While there has not been an independent evaluation, this increase appears to be because of improved supply chains, private-sector engagement, public commitment to reinstate and enforce iodization legislation, engagement by international agencies like UNICEF, and initiatives like the Micronutrient Initiative and the Global Alliance for Improved Nutrition.

This scale-up of coverage has led to improvements in the iodine status, mental development, and physical growth of Ethiopian children. In a 2014 randomized trial of children in 60 Ethiopian villages, the urinary iodine content, length for age, and scores on tests used to assess motor, language, and cognitive development were all higher for those children consuming iodized salt (Bougma et al. 2015).

The private sector played a leading role in this scale-up by (1) improving the cost structure of iodized salt to provide incentives for production, (2) improving access to potassium iodate $\left(\mathrm{KIO}_{3}\right)$, and

(3) implementing high-quality iodization processes.

First, the small-scale salt sector organized into cooperatives. Near Lake Afdera, where the majority of Ethiopia's salt is harvested, an overcrowding of salt producers following government incentives to increase salt production led to plummeting prices and inconsistencies in the supply of high-quality salt (Bagriansky 2014). In response, the producers banded together to coordinate production and fix quotas and prices, forming the Afar Salt Producers Mutual Support Association (ASPMSA). In late 2011, ASPMSA used its new supply coordination network to reengage producers to iodize their salt. The association worked with the government to distribute $\mathrm{KIO}_{3}$ to each producer, automatically deducting the cost of $\mathrm{KIO}_{3}$ from the producer's pay. This method effectively removed the incentive to increase profits by not iodizing (Chuko et al. 2015).

Second, ASPMSA supported the establishment of a cost recovery mechanism for $\mathrm{KIO}_{3}$ to ensure its sustainable supply for producers without the aid of continued outside donations. The design of the method ensured affordable access to $\mathrm{KIO}_{3}$, especially for small-scale producers
(Spohrer and Garrett 2013; Garrett and Prczewlofsky 2013). This new system has reduced and covered the cost of fortificants, shown to be one of the most significant barriers to adequate fortification (Luthringer et al. 2015).

Third, quality assurance practices are being built and are contributing to higher-quality iodized salt. From 2011 to 2014, the Global Alliance for Improved Nutrition donated iodization machines, which increase the quality and production volumes of adequately iodized salt compared with the former process of spraying iodine on salt. Producers have been trained on quantitative iodine analysis using donated rapid test kits or internal production laboratories, and food control inspectors have been added to better enforce regulations for iodized salt. Shewit Salt Processing, a major cooperative similar to ASPMSA, has also improved salt iodization quality by using better packaging and labeling practices to command higher market prices, and by securing land to expand its iodization facility.

Together these actions by the private sector, government, and technical agencies have led to rapid and sustainable improvements in iodine nutrition in Ethiopia.

However, some quality issues remain to be addressed in the salt iodization program in order to achieve more universal coverage of adequately iodized salt, which the private sector is well placed to deliver. probably represent a best-case scenario for coverage - they are where nongovernmental organizations can work and collect data-and they need to be placed in the public domain in an accessible and well-documented manner. At present they are not. Doing so would facilitate thorough analysis of the pattern and determinants of implementation, which would help policy and program implementers refine their strategies for improving SAM treatment.

Progress on scaling up interventions to reduce undernutrition worldwide has been slow and inequitable. One 


\section{PANEL 5.5 NONGOVERNMENTAL ORGANIZATIONS' SUPPORT FOR MICRONUTRIENT PROGRAMS IN BURKINA FASO}

\section{VICTORIA QUINN}

In Burkina Faso, major advances have included the industrial fortification of staple foods-a cost-effective strategy to reduce micronutrient deficiencies (Hoddinott et al. 2012; Das et al. 2013)_following passage of legislation for the mandatory fortification of cooking oil with vitamin $A$ and wheat flour with a range of nutrients including iron and folic acid. These products are now reaching more than 84 percent of the country's 18 million consumers.

These advances have been supported by Helen Keller International (HKI). Funding from the government of Taiwan enabled HKI to provide the technical assistance needed to reinforce local food industries' capacity to meet standards and assure quality. These fortified products are branded with the Enrichi fortification logo developed under a wider West African multipartner initiative spearheaded by HKI and other partners with multidonor funding, including from the US government. HKI has worked with governments and private food companies in 19 countries across Africa, where today it is estimated that 285 million consumers have access to such fortified foods.

HKI's commitment in Burkina Faso also entails building the evidence base on the impact of nutrition-sensitive agriculture. Along these lines, HKI partnered with the International Food Policy Research Institute and-together with local government health and agricultural offices, the National
Agricultural Research Institute, and a local NGO - concluded the first phase of a rigorous, community-randomized controlled trial of its well-known Enhanced Homestead Food Production model in Burkina Faso's Est (eastern) region with funding from the US government. Findings were published in 2015, showing for the first time ever that a well-designed, integrated program promoting nutrient-rich homestead food production, together with nutrition behavior change communication, can have a positive impact on maternal and child nutritional status (Olney et al. 2015). HKI's support for micronutrient programs in Burkina Faso was also a commitment made for N4G.

\section{FIGURE 5.6 Coverage estimates for management of severe acute malnutrition in 58 districts in 14 countries}

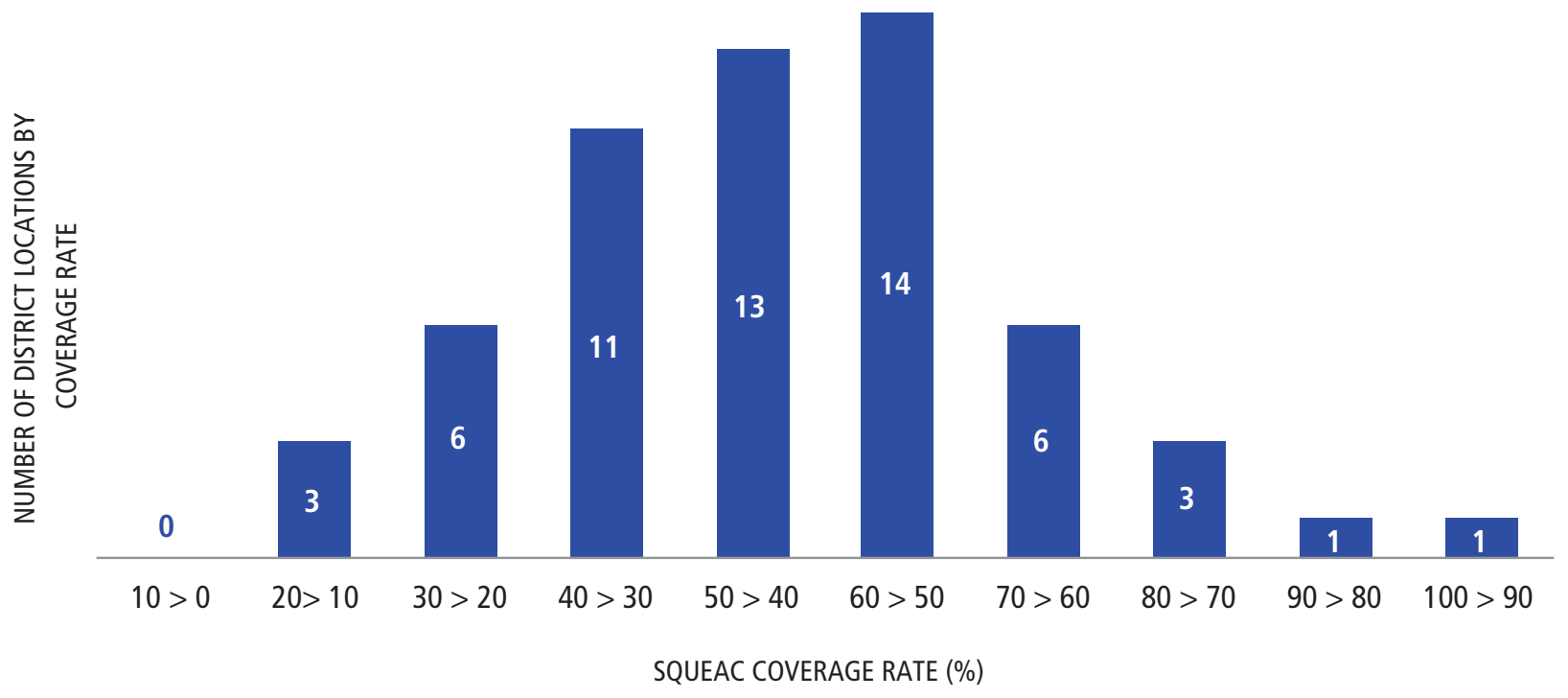

Source: Authors, based on data provided by Jose Luis Alvarez of the Coverage Monitoring Network, February 8, 2016.

Note: Estimates are produced by the SQUEAC (semi-quantitative evaluation of access and coverage) methodology. The 14 countries are Afghanistan, Burkina Faso, Central African Republic, Chad, Democratic Republic of the Congo, Ethiopia, Kenya, Mali, Niger, Nigeria, Pakistan, Senegal, Somalia, and South Sudan. 
way of advancing implementation to reach scale is through health systems, especially primary health care. Many health systems are already actively engaged in implementing direct nutrition interventions-for example, delivering iron and folic acid or multiple micronutrient supplements, calcium supplements, counseling on nutrition and early breastfeeding, and more through prenatal care. Experiences now exist with other services as well (infant feeding counseling, screening, referral and treatment of malnutrition), so it is an appropriate time to examine this issue more closely. There is also considerable alignment with health systems' actions to reduce child mortality, 45 percent of which is due to child undernutrition.

For example, in Ethiopia, the health extension system is taking on the delivery of nutrition interventions like infant feeding counseling and calcium supplementation. In India, the national rural health mission is taking on more work on nutrition-especially in the context of prenatal care provision, treatment of SAM, and micronutrient supplementation. In Viet Nam, the health system has embarked on an ambitious plan to integrate facility-based nutrition counseling on a large scale. In Bangladesh, the health sector development plan aims to "mainstream" nutrition into the health system. Efforts have been made through the integrated management of childhood illness (IMCI) approach to strengthen interventions for nutrition (for example, Arifeen et al. 2009).

But there are numerous challenges: the health system integration of nutrition in Bangladesh, for instance, worked much better for nutrition in prenatal care than in the provision of nutrition counseling to sick children; outreach services for preventive nutritional care, such as counseling and supplementation, were extremely difficult to establish (Saha et al. 2015). Even though IMCI guidelines, training, and tools are available, doctors providing care for sick children are busy and overburdened and therefore fail to follow many of the nutrition elements of the $\mathrm{IMCl}$ protocol (weighing children, assessing feeding, providing information on feeding).

Furthermore, plans to strengthen health systems are often slow to integrate actions that also strengthen the inclusion of nutrition interventions-especially preventive interventions in early childhood and those needed beyond age 5. Most health systems are focused on providing basic preventive care (immunization, prenatal care) and full-scale curative care. Many nutrition interventions are often in the middle of these types of services. Still, nutrition interventions such as micronutrient supplements, zinc along with oral rehydration solutions, and treatment of severe malnutrition in facilities fall well within routine health care activities. In many countries, health care systems are still far from being able to deliver some of the more "basic" health interventions-immunizations, basic prenatal care, birthing care-so nutrition services and interventions may be seen as nonessential.

As the global and national discourse unfolds on issues related to Sustainable Development Goal 3 ("Ensure healthy lives and promote well-being for all at all ages") and especially universal health care, it will be important to think about what this means for delivery of nutrition interventions as well. Health systems will need to be equipped to better integrate nutrition interventions at high coverage rates in the context of improving primary health care and reproductive, maternal, and child health services. Given common goals and the linkages between nutrition and health, strengthening these nutrition-health system linkages can be a potential win-win for the policy, program, and research communities that are engaged in strengthening health systems, scaling up nutrition, or both.

\section{CALLS TO ACTION}

\section{Strengthen interministerial task forces across malnutrition in all its forms. By the end of 2018,} all national governments should build interministerial task forces to implement nutrition policies, as well as national advisory councils or commissions. Such mechanisms should do the following:

- have a direct line to the office of the head of state;

- include bottom-up, social participation (for example, CSOs, social movements, and academia); and

- oversee the development and/or implementation of policies and programs to address malnutrition in all its forms.

In addition, by 2018 the donor community should provide funding for at least 25 such mechanisms, to allow them to build capacity and ensure that they are working effectively.

2. Convert recommendations into legislation. Governments should implement and monitor widely recommended policies and programs that support breastfeeding. Specifically, governments should make SMART commitments to

- implement all the provisions outlined in the International Code of Marketing of Breast-milk Substitutes by the time of the N4G event in 2020; and 
- ratify by 2020 the International Labour Organization's convention to provide maternity leave protection and other workplace support, and monitor and report on workplace policies for continued breastfeeding and child care.

3. Implement policies to support recommendations. Governments should implement and monitor widely recommended policies and programs that promote healthy diets, such as salt/sodium reduction policies (including legislated targets); policies to replace saturated fats and trans fats with unsaturated fats; restrictions on marketing of foods high in fats, sugars, and salt to children; and taxes on sugar-sweetened beverages. To date, only 10 percent of countries report progress on three core policies (implementing the World Health Organization's recommendations on marketing to children; salt reduction; and trans and saturated fat reduction). By 2030 all countries should be able to report significant progress on these three.

\section{Scale up the 13 proven nutrition-specific}

interventions. Governments and international stakeholders should work to scale up coverage of proven nutrition-specific interventions - at both the global and national levels - with a focus on integrating nutrition actions into health system platforms. Of the 13 interventions we review, the median coverage rate ranges from 1 to 79 percent. By 2030 the median coverage rate for all 13 should be 90 percent.

\section{Deepen understanding of scale-up and} quality implementation of all proven nutrition interventions. Researchers should explore the technical, political, and economic enablers of and barriers to the uptake, implementation, and enforcement of nutrition interventions. Areas where more research is needed include

- lessons learned from successful task forces and councils;

- why some countries achieve better coverage than others for a given nutrition-specific intervention, and why some nutrition-specific interventions are more scalable than others, even within the same country; and

- how incorporating proven nutrition-specific interventions into health systems affects nutrition and broader health outcomes.

By the end of 2018, research funders should have announced at least two major multicountry-funded research programs on the enablers of and barriers to uptake, implementation, and enforcement of proven nutrition policies and programs. 